\title{
Components of Conidial and Hyphal Walls of Penicillium chrysogenum
}

\author{
By V. RIZZA* AND J. M. KORNFELD \\ Microbiology Section, Biological Sciences Group, \\ University of Connecticut, Storrs, Connecticut 06268, U.S.A.
}

(Accepted for publication 30 June 1969)

SUMMARY

Cell walls were prepared mechanically from both hyphae and conidia of Penicillium chrysogenum. The major carbohydrate components of cell wall hydrolysates were glucose, galactose and glucosamine, with lesser amounts of mannose and rhamnose. The conidia were richer in galactose and the hyphae contained more glucosamine. The distribution of the monomers in acidsoluble and alkali-soluble fractions was different in the two kinds of cell wall; conidial walls contained higher concentrations and a greater variety of amino acids than hyphal walls.

\section{INTRODUCTION}

In contrast to the intensive investigations of the polymers constituting the cell walls of bacteria, the study of the structural macromolecules of the cell walls of filamentous fungi has been very limited. Many of these studies, dating from the last century, were restricted to histological observations (van Wisselingh, 1898; Melzer, 1924). More recent reports have been concerned with direct chemical analyses. In most cases (Hamilton \& Knight, 1962; Crook \& Johnston, 1962; Manocha \& Colvin, 1967; Applegarth, 1967), however, analyses have been restricted to only the hyphal stage in the developmental cycle, although the acetyl content of hyphal and spore walls of Asperigillus phoenicis has been compared (Bloomfield \& Alexander, 1967).

Penicillium chrysogenum, a filamentous fungus, possesses at least two morphologically distinct stages representing a seemingly primitive morphogenetic system. The conidia are oblate spheroids, green in colour, and possessing rigid cell walls, whereas the hyphae which develop from them are filamentous, flexible and white. These morphological differences suggest differences in chemistry. Mahadevan \& Tatum (I965) have detected a number of quantitative differences in the cell walls of a variety of mutants of Neurospora crassa. They concluded that the morphology is a direct consequence of the cell wall composition and that changes from wild-type growth to other forms may be caused by alterations in the relative concentrations of the structural polymers of the cell wall. It seems reasonable to expect that functionally comparable structures which differ morphologically at different stages in the life cycle of an organism would also differ chemically. Because of the paucity of comparative data and to uncover basic molecular changes in the conversion of conidium to hyphal cell, studies were undertaken to determine whether the cell walls of the two stages are, in fact, biochemically distinct.

* Present address: Department of Biochemistry, University of Kentucky School of Medicine, Lexington, Kentucky, U.S.A. 


\section{METHODS}

Organism and growth conditions. Penicillium chrysogenum, strain NRRL I95 I-B 25, was maintained on Sabouraud glucose (SG) slopes: $4 \%$ glucose, I \% 'neopeptone', $1.8 \%$ agar. After sporulation, the cultures were refrigerated.

Roux culture bottles containing SG agar were inoculated with conidia from sporulated slopes and incubated at ambient temperature (about $25^{\circ}$ ) until sporulation occurred, which was usually 4 days. Sterile water was added, and the conidia removed by scraping the surface with a sterile aluminium spatula. The conidial suspension was filtered through sterile Pyrex glass wool so that the spore harvest would be free from mycelial fragments, as verified by microscopic examination. After at least five cycles of washing and centrifugation, the conidia were suspended and maintained in cold M/I5 potassium phosphate buffer ( $\mathrm{pH} 7 \cdot 4$ ).

Hyphae were grown by inoculating a spore suspension into 61 . of SG broth in a Microferm Laboratory Fermentor (New Brunswick Scientific Co., Inc., New Brunswick, New Jersey, U.S.A.). Incubation continued for $48 \mathrm{hr}$ at ambient temperature under constant aeration and agitation. The hyphae were collected on filter paper and washed four times with cold distilled water.

Preparation of spore walls. Washed spores (Io g. wet weight) were suspended in Io ml. cold phosphate buffer ( $\left.\mathrm{pH}_{7} .4\right)$ to which $50 \mathrm{~g}$. of glass beads $(0.5 \mathrm{~mm}$. diameter) were added. Spores were disrupted in a Bronwill Mechanical Cell Homogenizer maintained at $5^{\circ}$. When disruption was essentially complete (as determined by the release of protein into the supernatant fluid and verified microscopically), homogenization was discontinued. The mixture was centrifuged at $500 \mathrm{~g}$ to separate the spore walls from the glass beads. The crude wall fraction was collected by centrifugation at $4000 \mathrm{~g}$. The pellet was suspended in 100 volumes of distilled water and agitated on a wrist action shaker overnight at $4^{\circ}$. The suspension was centrifuged and washed successively with distilled water and phosphate buffer ( $\mathrm{pH} 7 \cdot 4)$ until no extinction was detectable in the supernatant at $260 \mathrm{~m} \mu$ and $280 \mathrm{~m} \mu$, indicating the absence of cytoplasmic contaminants. After collection, the pellet was extracted for $\mathbf{I ~ h r}$ in each of the following solvents: $95 \%(\mathrm{v} / \mathrm{v})$ ethanol in water at $5^{\circ}$, three times with boiling ethanol + ether $(I+3, v / v)$, and finally boiling ether. After extraction the walls were lyophilized.

Preparation of hyphal walls. Hyphae were disrupted in a Sorvall Omnimixer (Ivan Sorvall, Inc., Norwalk, Connecticut, U.S.A.) with glass beads. Purification procedures were the same as described for the preparation of spore walls.

Isolation of carbohydrates. The procedure described by Mahadevan \& Tatum (1965) was adopted: $49 \mathrm{mg}$. samples of wall material were treated with $2 \mathrm{~N}-\mathrm{NaOH}$ for $16 \mathrm{hr}$ at room temperature, centrifuged, and the supernatant liquid treated with 2 vol. $95 \%$ (v/v) ethanol in water. The resulting precipitate was suspended in water, dialysed against water, and lyophilized; this fraction was designated $\mathrm{F}$ I. The residue remaining after the treatment with $\mathrm{NaOH}$ was resuspended in $\mathrm{N}$-sulphuric acid, incubated at $90^{\circ}$ for $\mathrm{I} 6 \mathrm{hr}$ and centrifuged. The pellet was washed and the washings were added to the supernatant fluid. The supernatant fluid was adjusted to $\mathrm{pH} 7$ with $\mathrm{Ba}(\mathrm{OH})_{2}$, and the resulting precipitate was removed by centrifugation and discarded; the material in the supernatant fluid was designated $F 2$. The residue remaining from the sulphuric acid treatment was resuspended in $2 \mathrm{~N}-\mathrm{NaOH}$ for $30 \mathrm{~min}$. at room temperature and 
centrifuged and 2 vol. ethanol added to the supernatant liquid. The precipitate was centrifuged down, suspended in water, dialysed against water, and lyophilized; this fraction was designated $\mathrm{F}_{3}$. The residue from the second $\mathrm{NaOH}$ treatment was suspended in water, dialysed, lyophilized, and designated $\mathrm{F} 4$. Before electrophoresis, the fractions were hydrolysed according to the procedure of Mahadevan \& Tatum (1965).

Extraction of amino acids. Samples $(50 \mathrm{mg}$.) of either conidial or hyphal walls were heated in $6 \mathrm{~N}-\mathrm{HCl}$ in evacuated tubes at $105^{\circ}$ for $\mathrm{I} 8 \mathrm{hr}$. The hydrolysates were filtered through 'Millipore' filters. The filtrates were taken to dryness by heating in vacuo in a hot water bath. Each hydrolysate was dissolved in $\mathrm{I} \mathrm{ml} .10 \%(\mathrm{v} / \mathrm{v})$ isopropanol in water and stored at $0^{\circ}$.

Separation of components. Separation of amino acids was accomplished by electrophoresis with the high voltage electrophorator, Model D (Gilson Medical Electronics, Middletown, Wisconsin, U.S.A.). Hydrolysate samples or standards were applied at $5 \mathrm{~cm}$. intervals parallel to the short side along an origin line drawn $12 \cdot 7 \mathrm{~cm}$. from the end of a $46.4 \times 57 \cdot 2 \mathrm{~cm}$. sheet of Whatman $3 \mathrm{MM}$ chromatography paper. The paper was then sprayed with a mixture of formic acid +acetic acid +water $(6+24+170$ by vol.) at $\mathrm{pH} 2$ until wet and transferred to the electrophoresis tank with the origin line proximal to the anode. The samples were run in the same buffer at $30 \mathrm{~V} / \mathrm{cm}$., current 80 to $85 \mathrm{~mA}$, for $90 \mathrm{~min}$. at Io to $12^{\circ}$. After electrophoresis, the paper was dried at $90^{\circ}$ for $20 \mathrm{~min}$. Neutral sugars were run in a boric acid buffer adjusted with $\mathrm{NaOH}$ to $\mathrm{pH} 9.4$ at $240 \mathrm{~V} / \mathrm{cm}$., current 4 to $5 \mathrm{~mA}$, for $150 \mathrm{~min}$. at io to $15^{\circ}$. After removal from the electrophoresis chamber, the paper was dried as described above. Because of trailing, the resolution obtained with amino sugars upon direct electrophoresis was insufficient for identification or quantitation, so the samples were oxidized with ninhydrin before electrophoresis; this converted any hexosamines present to their corresponding pentoses (Stoffyn \& Jeanloz, 1954). The oxidized samples were run as described for neutral sugars.

Amino acids were made visible by dipping the electrophoretograms in $1 \cdot 5 \%$ ninhydrin in $95 \%(\mathrm{v} / \mathrm{v})$ ethanol in water, drying at room temperature and counterstaining with a cupric nitrate solution (Mabry \& Todd, 1963). Sugars were made visible with the diphenylamine-p-anisidine reagent (Mabry, Gryboski \& Karam, 1965).

In situations where components could not be separated by electrophoresis, the electrophoretograms were cut into strips parallel to the direction of migration. The strips were sewn on to Whatman No. I paper and chromatographed in the second dimension with 2-butanone + propionic acid + water $(75+25+30$, by vol.). By this procedure, amino acids which had similar electrophoretic mobilities were separated and amino acids whose mobility properties left them within the glucosamine streak were resolved.

Identification and estimation of components. The amino acids and sugars were identified by three properties: (I) electrophoretic mobility compared with standard samples run simultaneously; (2) characteristic tints after colour development; (3) rates of colour development. Electrophoretic mobility values were also compared with published values (Mabry \& Todd, 1963; Himes \& Metcalfe, 1959).

Quantitative estimates were made by cutting the developed sheets into strips $3.2 \mathrm{~cm}$. wide and scanning them in a Model RB Analytrol densitometer-integrator (Spinco Division, Beckman Instruments, Inc., Palo Alto, California, U.S.A.). For the amino 
acids, $500 \mathrm{~m} \mu$ interference filters were used, and for the sugars, $450 \mathrm{~m} \mu$ interference filters. Proportionality between integration units and concentration was obtained in the range 0 to $400 \mu \mathrm{g}$. for the sugars and o to $100 \mu \mathrm{g}$. for the amino acids.

Nitrogen analysis. Nitrogen was determined as ammonia by the Kjeldahl-Nessler method described by Wilson \& Knight (1952).

\section{RESULTS}

The distribution of monosaccharides in hydrolysates of the series of extracts from conidial and hyphal cell walls is shown in Table I. The first alkali-soluble fraction (F I) of conidial walls contained glucose, galactose and mannose. Hydrolysis of hyphal F I also gave glucose and galactose, but no mannose. Quantitatively, the two fractions differed markedly in the relative amounts of glucose and galactose. The glucose : galactose ratio of conidial $F_{I}$ was 0.32 , whereas in hyphal $F_{I}$, the ratio was $7 \cdot 5$. The total weight of the two fractions were similar, conidial $F_{\text {I }}$ being slightly greater.

Table I. Distribution of monosaccharides in the fractions obtained by sequential extraction of conidial and hyphal walls of Penicillium chrysogenum

\begin{tabular}{|c|c|c|c|c|c|c|c|c|c|c|c|c|c|}
\hline & \multicolumn{4}{|c|}{ Conidial walls } & & & \multicolumn{4}{|c|}{ Hyphal walls } & \multirow[b]{2}{*}{ Total } & \multirow[b]{2}{*}{$\begin{array}{l}\text { Mole } \\
\text { ratio }\end{array}$} & \multirow[b]{2}{*}{$\begin{array}{c}\text { Mole* } \\
\text { ratio }\end{array}$} \\
\hline & F I & $\begin{array}{c}F_{2} \\
\text { ng. } / 100\end{array}$ & $\begin{array}{c}\mathrm{F}_{3} \\
\mathrm{mg} . \text { wall }\end{array}$ & $\mathbf{F 4}$ & Total & $\begin{array}{l}\text { Mole } \\
\text { ratio }\end{array}$ & F I & $\begin{array}{c}F_{2} \\
\text { ng. } / 100\end{array}$ & $\begin{array}{c}\mathrm{F}_{3} \\
\text { mg. wall) }\end{array}$ & $F_{4}$ & & & \\
\hline Glucose & $6 \cdot 12$ & 5.92 & $14 \cdot 30$ & - & $26 \cdot 34$ & 10.23 & $15 \cdot 31$ & $12 \cdot 24$ & $6 \cdot 33$ & - & $33 \cdot 88$ & $12 \cdot 77$ & $8 \cdot 8$ \\
\hline Galactose & 18.80 & $0.6 \mathrm{r}$ & - & - & $19 \cdot 41$ & 7.54 & 2.04 & $5 \cdot 10$ & - & - & $7 \cdot 14$ & $2 \cdot 70$ & $2 \cdot 7$ \\
\hline Mannose & $2 \cdot 25$ & 0.33 & - & - & $2 \cdot 58$ & 1.00 & - & 2.65 & - & - & 2.65 & I.0o & $I \cdot O$ \\
\hline Rhamnose & - & 0.31 & - & - & 0.31 & 0.13 & - & 0.88 & - & - & 0.88 & 0.37 & 0.5 \\
\hline Glucosamine & - & 4.08 & - & $7 \cdot 35$ & $I I \cdot 43$ & 4.49 & - & $9 \cdot 39$ & - & $8 \cdot 57$ & 17.96 & 6.86 & 4.4 \\
\hline Residue & 6.95 & - & - & I1.02 & 17.97 & - & $10 \cdot 20$ & - & $5 \cdot 72$ & $6 \cdot 12$ & $22 \cdot 04$ & - & - \\
\hline Total & $34 \cdot 12$ & II $\cdot 25$ & $14 \cdot 30$ & $18 \cdot 37$ & $78 \cdot 04$ & - & 27.55 & $30 \cdot 26$ & $12 \cdot 05$ & $\times 4 \cdot 69$ & 84.55 & - & - \\
\hline
\end{tabular}

Both $\mathrm{F}$ I fractions were non-dialysable and could be precipitated from $\mathrm{NaOH}$ with ethanol or ammonium sulphate. However, the conidial $F_{I}$ was dark green, which was not the case with hyphal F I. Despite the intense colour, no extinction bands were detectable in a scan of the material in the visible spectrum. The extinction curve obtained was suggestive of light scattering of sufficient intensity to mask any specific absorption bands. On standing at room temperature for extended periods of time, the colour passed through a dull brown colour to a mustard yellow. This colour change was accelerated by reducing agents, e.g. sodium dithionite, and reversed by hydrogen peroxide. The hyphal FI, in contrast, did not exhibit these oxidation-reduction characteristics. The nature and function of the green pigment is unknown.

The F 2 fractions of conidial and hyphal walls contained all five detectable monosaccharides. However, they differed quantitatively, each monosaccharide being present in higher concentration in the hyphal walls. Consequently, hyphal $\mathrm{F} 2$ constituted a significantly greater fraction $(30 \%)$ than conidial F 2 ( $11 \%$ ).

The two fractions $\mathrm{F}_{3}$ and $\mathrm{F}_{4}$ appeared to be the only homopolymeric fractions. On hydrolysis, F 3 gave only glucose, and F 4 only glucosamine. There were about the same amounts of glucosamine in the $\mathrm{F}_{4}$ fractions of either wall. The conidial $\mathrm{F}_{3}$ contained twice as much glucose as in hyphal $\mathrm{F} 3$.

Comparison of the total amounts of each monosaccharide indicates that only galactose and glucosamine differed markedly in the two kinds of wall. The galactose 
content of the conidial walls was $2 \cdot 7$ times that found in the hyphal walls. The hyphal walls, on the other hand, were richer in glucosamine, containing 1.6 times that found in conidial walls. Glucose was present at slightly greater concentration in the hyphal walls. Although the rhamnose content of hyphal walls was greater than in conidial walls, the concentrations in both kinds of wall was sufficiently low so that rhamnose may be described as a minor component.

Other differences in the composition of the cell walls became apparent from the distribution of the monosaccharides in the several fractions. All of the mannose of hyphal walls was in the $F_{2}$ fraction, whereas virtually all appeared in fraction $F_{1}$ of conidial walls. Although glucose was found in fractions $F_{1}, F_{2}$ and $F_{3}$ of both types of walls, it was concentrated in $F_{3}$ in conidial walls, whereas it was present in largest amounts in F I and F 2 of hyphal walls. Essentially all of the galactose of conidial walls was recovered in FI, but in hyphal walls it was found in FI and in F 2, with $70 \%$ of the total galactose in F 2 . Glucosamine was found at about the same concentration in $\mathrm{F} 4$ of both hyphal and conidial walls. However, hyphal $\mathrm{F} 2$ contained significantly more glucosamine than did conidial $\mathrm{F} 2$.

Included in Table I are mole ratios for monosaccharide components of Penicillium chrysogenum hyphal walls reported by Hamilton \& Knight (1962). The present results appear to be in good agreement with those data for galactose, mannose and rhamnose, but are high with respect to glucose and glucosamine. In the paper by Hamilton \& Knight (1962), xylose was reported as a component of the hyphal walls; this pentose has also been reported as a trace component in $P$. digitatum and $P$. italicum (Grisaro, Sharon, \& Barkai-Golan, 1968). Although the presence of xylose had been expected, we found no xylose in the hydrolysates of any fraction. Neither Crook \& Johnston (1962) nor Applegarth (1967) detected xylose in hydrolysates of the closely related $P$. notatum. Since the organism used in the present work is the strain Hamilton \& Knight (1962) used, it seems likely that the absence of xylose had resulted from differences in growth conditions.

Table 2. Amino acid components of conidial and hyphal walls of Penicillium chrysogenum

\begin{tabular}{|c|c|c|c|c|}
\hline \multirow[b]{2}{*}{ Amino acid } & \multicolumn{2}{|c|}{ Conidial walls } & \multicolumn{2}{|c|}{ Hyphal walls } \\
\hline & (mg./soo mg. wall) & Mole ratio & (mg./100 mg. wall) & Mole ratio \\
\hline Aspartic acid & 3.92 & $\mathrm{I} \cdot 73$ & 0.61 & $3 \cdot 40$ \\
\hline Glutamic acid & $2 \cdot 78$ & $I \cdot I O$ & 0.29 & $I \cdot 46$ \\
\hline Threonine & 0.25 & 0.12 & - & - \\
\hline Leucine & 0.83 & 0.38 & 0.22 & $I \cdot I 7$ \\
\hline Isoleucine & 0.83 & 0.38 & 0.20 & $I \cdot I 3$ \\
\hline Valine & $1 \cdot 22$ & 0.61 & 0.20 & I $\cdot 27$ \\
\hline Serine & 0.67 & 0.38 & 0.13 & 0.92 \\
\hline Alanine & $x \cdot 51$ & $1 \cdot 00$ & 0.12 & $I \cdot \infty$ \\
\hline Glycine & $\mathrm{I} \cdot 47$ & $1 \cdot 15$ & - & - \\
\hline Arginine & I $\cdot 88$ & 0.64 & - & - \\
\hline Lysine & $1 \cdot 58$ & 0.64 & 一 & 一 \\
\hline Total & 16.94 & - & I $\cdot 77$ & 一 \\
\hline
\end{tabular}

The amino acid composition of the two types of wall differed not only in total amount and relative proportions, but qualitatively as well (Table 2). No tyrosine, phenylalanine, tryptophan, cysteine, methionine or histidine was detected in the conidial or hyphal walls. Furthermore, hyphal walls did not contain any glycine, 
threonine, lysine or arginine, all of which were found in conidial walls. The absence of these amino acids raised the question of their possible destruction during hydrolysis. There have been reports of the degradation of aromatic and sulphur-bearing amino acids during acid hydrolysis in the presence of carbohydrate (Lugg, I933, 1938). However, all of these absent amino acids have been recovered in acid hydrolysates of Penicillium notatum hyphal walls, with the exception of methionine (Crook \& Johnston, 1962) and tryptophan (Applegarth, 1967). Since the carbohydrate content of $P$. notatum does not differ significantly from $P$. chrysogenum, and the conditions of hydrolysis in those studies were essentially the same as used here, it appears unlikely that the amino acids absent from the hydrolysates, with the possible exception of methionine and tryptophan, were initially present in either complex. With respect to the four amino acids found in conidial wall hydrolysates (arginine, lysine, threonine, glycine) but not found in hyphal wall hydrolysates, there is little doubt that they were not part of the hyphal wall complex. Had they been present initially in the hyphal walls, one would expect that their destruction would have occurred during hydrolysis of both conidial and hyphal walls, since both kinds of walls contain approximately the same amount of carbohydrate and were hydrolysed under identical conditions.

The amino acid data for hyphal walls are not in agreement with the values reported for hyphal walls of Penicillium notatum by Applegarth (1967) who found threonine, glycine, arginine and lysine as components of hyphal wall hydrolysates, the latter two as major constituents (all absent from hyphal walls in $P$. chrysogenum).

Quantitatively, the most significant difference appears in the total amino acid content of the two types of wall of Penicillium chrysogenum. Conidial walls appeared to contain Io times as much amino acid as hyphal walls. The value of $\mathrm{I} \cdot 77 \%$ for total amino acid is in good agreement with the figure of $2 \%$ suggested by Hamilton \& Knight (1962) for hyphal walls of the same organism.

Table 3. Recovery of nitrogen in hydrolysate components and in Kjeldahl digests of conidial and hyphal walls of Penicillium chrysogenum

Calculated from components

Amino Acid $N$

Glucosamine $\mathbf{N}$

Total $\mathbf{N}$

Found in Kjeldahl digests of walls

Calculated/found $\times$ 100

$\begin{array}{cc}\begin{array}{c}\text { Spore wall } \\ (\mu \mathrm{g} . \mathrm{N} / \mathrm{mg} \text {. wall })\end{array} & \begin{array}{c}\text { Hyphal wall } \\ (\mu \mathrm{g} . \mathrm{N} / \mathrm{mg} \text {. wall })\end{array} \\ 24 \cdot 60 & \mathrm{I} \cdot 97 \\ 8 \cdot 99 & 14 \cdot \mathrm{I} \text { I } \\ 33 \cdot 59 & 16 \cdot 08 \\ 36 \cdot 57 & 17 \cdot 00 \\ 91 \cdot 8 \% & 94 \cdot 6 \%\end{array}$

When the total contributions of each of the nitrogen-containing components are summed, excellent agreement is obtained with the direct nitrogen analysis of walls (Table 3), 92\% of conidial wall nitrogen and $95 \%$ of hyphal wall nitrogen can be accounted for as glucosamine and amino acids; the data support the validity of the quantitative method used, and the high recovery of nitrogen supports the contention that certain amino acids were not present in the cell walls. 


\section{DISCUSSION}

The significance of any analyses of fungal cell walls, particularly in regard to amino acid composition, depends upon the purity of the preparation. The 'cleanliness' of wall preparations has been judged by a variety of criteria. Crook \& Johnston (I962) considered the isolation of the walls to be complete when all materials which stained intensely with methylene blue had been removed, or, as in the cases of Sporobolomyces roseus and Penicillium notatum, when cytoplasmic particles could not be detected by examination with the electron microscope. Applegarth (1967) washed the disrupted hyphae of $P$. notatum several times, but still detected some protein contamination of the preparation by electron microscopy. He then treated the material with $0 \cdot 1 \%$ trypsin for $24 \mathrm{hr}$, after which electron microscopic examination showed a 'good' wall preparation. Mahadevan \& Tatum (1965) washed the disrupted hyphae of Neurospora crassa with water and increasing concentrations of ethanol and determined the cleanliness of the material by microscopic examination. In the present work, the cell walls were judged pure when ultraviolet absorbing material was no longer released during the series of washings described. None of these criteria, however, is wholly reliable for judging the purity of walls, since adsorbed materials would not be detected. Even if it could be demonstrated unequivocally that the wall preparations were uncontaminated by cytoplasmic material, the preparations might differ from the native complexes. In preparations treated with lytic enzymes after disruption but before hydrolysis, it is difficult to determine whether the enzyme treatment is removing contaminating substances or removing material native to the complex as well or if the enzyme has become adsorbed. An indication that the walls used in the present work were not contaminated by cytoplasmic material is that the preparations lacked several amino acids normally found in proteins. The absence of these amino acids also argues for the absence of cytoplasmic membranes if the assumption is made that fungal membranes are similar to bacterial membranes, which contain all the known amino acids (Weibull \& Bergstrom, 1958; Brown, I96I; Yudkin, I966). The alternative assumption, that fungal membranes are radically different from bacterial membranes and do not contain certain amino acids allows for the possibility of membrane contamination. This appears to be unlikely, since the data would require not only that hyphal membrane be different from conidial membrane, containing even fewer amino acids, but in addition, the amino acids present in the two types of membrane would have to be present in different proportions.

Some insight into the nature of the polymers is provided by the data. In both types of wall, the $\mathrm{F}_{3}$ fraction is probably a glucan. A similar fraction has been isolated from hyphal walls of Neurospora crassa which was susceptible to the $\beta$-I,3-glucanase complex derived from Streptomyces C-3 (Mahadevan \& Tatum, 1965). The finding of only glucosamine in the $\mathrm{F}_{4}$ fractions suggests a chitinous material, as was reported for the F 4 fraction of $N$. crassa. Such components have also been reported for other fungi (Applegarth, 1967; Chattaway, Holmes \& Barlow, 1968; Grisaro et al. 1968). The kinds of polymers in our F I and F 2 fractions are considerably in doubt, since these fractions are so complex. No information is available whether these multicomponent fractions represent sets of homopolymers or heteropolymers. Possibly, there might be micelles of one polymer embedded within a matrix of another polymer. Some of the polymers of Penicillium chrysogenum hyphal wall have been degraded enzymically 
(Horikoshi, Koffler \& Garner, I96I ; Troy \& Koffler, I966), but enzymic digestion of conidial wall fractions has not been attempted. Intact conidia, however, have been treated in this laboratory with a variety of enzymes in an attempt to produce conidial protoplasts, but unsuccessfully. The intact conidia were resistant to the action of 'Pronase' chitinase, keratinase and the complex of enzymes derived from snail digestive juice. That conidia are refractory to snail enzyme has been corroborated by C. C. Remsen (personal communication). Hyphal walls of Aspergillus phoenicis are extensively digested by a mixture of purified chitinase and $B$-I, 3-glucanase, but the conidia of this organism are resistant to these enzymes, although they contain both glucose and $\mathrm{N}$-acetylhexosamine in their walls (Bloomfield \& Alexander, 1967).

The data in Table I suggest the possibility of a lamellar arrangement of wall polymers. Most of the glucose in the conidial walls was released by the second $\mathrm{NaOH}$ treatment, rather than the first, and thus required the acid extraction between the $\mathrm{NaOH}$ treatments in order to be solubilized. It seems likely, therefore, that the $\mathrm{F}_{3}$ fraction, in which most of the glucose is located, is covered by a base-resistant material which prevents $\mathrm{F}_{3}$ from being solubilized simultaneously with F I. Similar arguments could be advanced for the fact that glucosamine appears in both $F_{2}$ and $F_{4}$, rather than F 2 only. Preliminary examination of thin sections of conidia by electron microscopy appear to substantiate the presence of a lamellar array. The inability to convert conidia to protoplasts, therefore, may have resulted from the absence of one or more of the enzymes necessary for the sequential hydrolysis of the several major structural polymers of the cell wall.

The differences in distribution and concentration of the sugars and amino acids clearly indicates that conidial and hyphal walls are biochemically distinct.

\section{REFERENCES}

Applegarth, D. A. (1967). The cell wall of Penicillium notatum. Archs Biochem. Biophys. 120, 47 I.

Bloomfield, B. J. \& AleXander, M. (1967). Melanins and resistance of fungi to lysis. J. Bact. 93, 1276.

Brown, J. W. (1961). Composition of fractions prepared from Sarcina lutea protoplasts. Biochem. biophys. Acta 52, 368.

Chattaway, F. W., Holmes, M. R. \& Barlow, A. S. E. (1968). Cell wall composition of the mycelial and blastospore forms of Candida albicans. J. gen. Microbiol. 51, 367.

Crook, E. M. \& Johnston, I. R. (I962). The qualitative analysis of the cell walls of selected species of fungi. Biochem. J. 83, 325.

Grisaro, V., Sharon, N. \& Barkai-Golan, R. (1968). The chemical composition of the cell walls of Penicillium digitatum Sacc. and Penicillium italicum Whem. J. gen. Microbiol. 51, 145.

Hamilton, P. B. \& KNIGHT, S. G. (1962). An analysis of the cell walls of Penicillium chrysogenum. Archs Biochem. Biophys. 99, 282.

Himes, J. B. \& Mrtcalfe, L. D. (1959). Rapid quantitative determination of amino acids by high temperature paper chromatography. Analyt. Chem. 31, 192.

Horikoshi, K., Koffler, H. \& GARNeR, H. R. (I96I). Demonstration of laminarin in fungal cell walls. Bact. Proc. p. 95.

LuGG, J. W. H. (1933). Some sources of error in the estimation of cysteine and cystine in complex materials when acid hydrolysis is employed. Biochem. J. 27, 1023.

LUGG, J. W. H. (1938). Investigation of sources of error in the estimation of tyrosine and tryptophan in complex materials which are associated with hydrolysis. Biochem. J. 32, 775 .

MABRY, C. C., Gryboski, D. J. \& Karam, E. A. (1965). Rapid identification and measurements of mono- and oligosaccharides: an adaptation of high voltage electrophoresis for sugars and its application to biological materials. J. Lab. clin. Med. 62, 817 . 
MABRY, C. C. \& TODD, J. M. (1963). Quantitative measurements of individual and total free amino acids in urine. J. Lab. clin. Med. 6r, 146.

MahadeVAn, P. R. \& TAtUm, E. L. (1965). Relationship of the major constituents of the Neurospora crassa cell wall to wild type and colonial morphology. J. Bact. 90, I073.

Manocha, M. S. \& Colvin, J. R. (1967). Structure and composition of the cell wall of Neurospora crassa. J. Bact. 94, 202.

Melzer, M. V. (1924). L'ornementation des spores de Russules. Bull. Soc. mycol. Fr. 40, 78.

Stoffyn, P. J. \& JeANLOZ, R. W. (1954). Identification of amino sugars by paper chromatography. Archs Biochem. Biophys. 52, 373.

Troy, A. F. \& KoffLer, H. (I966). The chemistry of fungal cell walls as studied by enzymic dissection. Fedn Proc. Fedn. Am. Socs exp. Biol. 25, 410.

Weibull, C. \& Bergstrom, L. (1958). The chemical nature of the cytoplasmic membrane and cell wall of Bacillus megaterium, strain M. Biochim. biophys. Acta 30, 340 .

Wilson, P. W. \& KNIGHT, S. G. (1952). Experiments in Bacterial Physiology, 3rd ed. Minneapolis: Burgess Publishing Co.

van Wisselingh, C. (1898). Mikrochemische untersuchungen uber die Zellwănde der Fungi. $J b$. wiss. Bot. 3r, 619.

YUDKIN, M. D. (1966). Isolation and analysis of the protoplast membrane of Bacillus megaterium. Biochem. J. 98, 923. 